\title{
"O TEMPO ABRE AS PORTAS A QUEM SABE ESPERAR": USOS DO PASSADO E EMBATES DO PRESENTE NO PERCURSO DA EXPOSIÇÃO REALIZADA NA PENITENCIÁRIA DE FLORIANÓPOLIS (SC)
}

\section{“TIME OPENS THE DOORS TO THOSE WHO WAIT": USES OF THE PAST AND CONFLICTS IN THE PRESENT DURING THE EXHIBITION HELD AT THE PENITENTIARY OF FLORIANÓPOLIS (SC)}

Viviane Trindade Borges*

\begin{abstract}
Resumo: A Penitenciária de Florianópolis foi inaugurada em 1930, em uma área considerada longe do centro urbano, logo absorvida por um bairro residencial. A partir de 1980, as fugas e as rebeliões passaram a amedrontar os moradores, fazendo da transferência do Complexo uma demanda constante. Em contrapartida, tal discussão evidencia a emergência da memória como uma das preocupações políticas e culturais da contemporaneidade, pois uma parcela da população confere importância histórica ao lugar, discurso este corroborado por alguns detentos, convidados a pensar sobre a proposta de tornar a velha Penitenciaria um museu. Tal discussão deu origem ao Espaço Memória da Penitenciária (2011). A presente comunicação trata dos desafios enfrentados ao tornar este espaço campo de estágio da disciplina Patrimônio Cultural, do curso de história da UDESC, propondo a salvaguarda de parte do acervo e a organização de uma pequena exposição, intitulada $O$ tempo abre as portas a quem sabe esperar (2012), a qual abrange um período de vai de 1930 até 1970.
\end{abstract}

\footnotetext{
* Professora no Curso de Graduação e no Programa de Pós-Graduação em História da Universidade do Estado de Santa Catarina (UDESC) e no Mestrado Profissional em Ensino de História da mesma universidade. E-mail: vivianetborges@gmail.com
} 
A administração deste passado traz a tona um tempo em que presos e comunidade tinham uma convivência muito próxima, evidenciada através de imagens de eventos e torneios que marcavam a Semana de Sentenciado, proibida em 1986, quando ocorreu a maior rebelião do Estado. Entrar neste espaço marginalizado, fazer dele um campo de estágio para historiadores em formação, criar uma exposição que trata de um outro tempo, onde outras relações eram possíveis, incita a reflexão a respeito dos novos usos do passado. Pode este passado mediado pelas técnicas pedagógicas e performativas da história, reverberar no social, contribuindo como estratégia humanizadora? Até que ponto a administração deste passado pode provocar a reflexão e despertar a consciência critica sobre os rumos do sistema penal? São algumas questões a serem perscrutadas.

Palavras-chave: Exposição. Penitenciária. Patrimônio. Lugar de memória.

Abstract: The Penitentiary in Florianópolis was inaugurated in 1930, in an area considered far from the urban center, soon absorbed by a residential neighborhood. Since 1980, leaks and rebellions began to frighten residents, making the transfer of the Complex a constant demand. In contrast, this discussion highlights the emergence of memory as one of the concerns of contemporary political and cultural, because a portion of the population gives historical significance to the place, this speech corroborated by some detainees, asked to think about the proposal to make the old one Penitentiary museum. This discussion led to Memory Space Prison (2011). This communication addresses the challenges faced in making this space field of Cultural Heritage stage of discipline, the course of history UDESC, proposing to safeguard part of the collection and organization of a small exhibition, titled The time opens the door to maybe wait (2012), which covers a period going from 1930 until 1970. The past administration of this brings up a time that prisoners and community had a very close interaction, evidenced by images of events and tournaments that marked the Week of Sentenced, banned in 1986, when there was the greatest rebellion of State. Entering this marginalized space, make him a training field for historians in training, to create an exhibition that comes from another time, where other relations were possible, encourages reflection about new uses of the past. Can this past mediated performative and pedagogical techniques of history reverberate in society, contributing to humanizing strategy? To what extent the administration of this past can provoke reflection and raise awareness about the critical paths of the penal system? Are some issues to perscrutadas.

Keywords: Exposure. Prison. Property. Place of memory. 


\section{"O TEMPO ABRE AS PORTAS A QUEM SABE ESPERAR"}

Grades abrindo, grades fechando, olhares lançados, olhares proibidos ("não olhem para esquerda", disse a certa altura o agente, "eles não gostam que olhem quando estão recebendo visitas). Fomos obedientes, acho que não saberíamos agir de outra forma, o agente nos explicava sobre a divisão interna do espaço, as tentativas comunicação através cobertores coloridos pendurados nas grades, os uniformes laranjas, os cubículos, o trabalho. Chamaram dois sentenciados para conversar conosco, separados por uma grade, vários agentes observado e eu ali, responsável por um grupo de alunos, como que diante de uma fonte antiga, escrita em português arcaico, que sabemos tratar de nossa língua, mas ainda assim não conseguimos decifrar. Achei que os alunos ficariam em silencio, e que eu, como professora, teria o dever de perguntar. Ledo engano. Os estudantes fizeram perguntas, queriam saber das histórias pregressas, das razoes que que levaram a prisão, da vida lá dentro. Conversaram sem nenhum constrangimento, e eu percebi que este seria um trabalho que deixaria marcas, que incitaria a reflexão. Nesse dia, ao sair, próximo a última grade que separa o sentenciado do mundo exterior, nos deparamos com a frase: "O tempo abre as portas a quem sabe esperar". Impactados pela visita, gravamos esses dizeres como inspiração para nosso trabalho, a realização de uma pequena exposição dentro do Complexo Penitenciário de Florianópolis.

A antiga "Penitenciária da Pedra Grande", atual Penitenciária de Florianópolis, foi inaugurada em 21 de Setembro de 1930 por intermédio da Lei ${ }^{\circ}$ 1.547, de Outubro de 1926. O local escolhido foi o Bairro Agronômica, então considerado distante do centro da cidade. Com o tempo a área ocupada passou a ser questionada, visto que a região tornou-se um bairro residencial de significativo valor imobiliário. Desta forma, as fugas e rebeliões passaram a atormentar os moradores locais, que pressionam as autoridades para que seja realizada a transferência da Penitenciaria. ${ }^{2}$

A presença dos desviantes e do espaço prisional em frente a um dos cartões postais da cidade, a Avenida Beira Mar Norte, tornou-se um problema constante para as autoridades locais e uma demanda social de ampla e controversa discussão. A transferência gera embates quer pela lentidão com que as decisões são tomadas, quer pelas negativas dos municípios selecionados para abrigar o novo espaço. Somam-se a estas, reinvindicações ligadas ao tombamento parcial do Complexo, ressaltando "o valor histórico do imóvel, inclusive por sua adequação com o passado da região". ${ }^{3}$

A proposta era tornar a Penitenciária campo de estágio dos acadêmicos do curso de história da Universidade do Estado de Santa Catarina (UDESC), da disciplina Prática Curricular Patrimônio Cultural, por mim orientados. Ligada ao Laboratório de Patrimônio Cultural da UDESC (LabPac/UDESC), a disciplina, procura estimular a reflexão a respeito de ações de preservação de 
bens culturais, ressaltando o papel dos historiadores e dos acervos no registro das experiências históricas e nos processos sociais de construção de memórias, propondo ações em instituições de salvaguarda.

Em nossa primeira incursão à Penitenciária, além de conhecermos os meandros do Complexo, visitamos o prédio administrativo, e no segundo andar, em um amplo saguão com vista para a Avenida Beira Mar Norte, nos deparamos com o chamado Espaço Memória da Penitenciária, que havia sido inaugurado em 21 de setembro de 2011, quando a Penitenciária de Florianópolis comemorou seus 81 anos de existência. $\mathrm{O}$ espaço era constituído por uma exposição, composta por fotografias e objetos sem identificação e/ ou cuidados relacionados à preservação, comprometendo a integridade física do acervo. Foi então que surgiu a ideia sobre a intervenção a ser realizada: a realização de uma nova exposição de longa duração junto ao Espaço Memória da Penitenciária. A partir de então, com o apoio da direção atual, foi consolidada uma parceria entre o Laboratório de Patrimônio Cultural da UDESC (LabPac/UDESC) e a Penitenciária, possibilitando a exposição e visando salvaguardar o acervo da instituição, consolidando um novo campo de estágio para os alunos do curso de história da UDESC. ${ }^{4}$

A existência de um espaço de celebração do passado dentro de uma prisão possui a função de dar a ver a história da instituição, principalmente à funcionários e familiares de detentos. Através da exposição de documentos e objetos antigos, valorizando a história institucional e ressaltando sua importância para o Estado, as instituições parecem buscar "entender o que foram para compreender como são (ou como desejam ser)". ${ }^{5}$ Sintoma do que podemos chamar de "cultura da memória"6 que perpassa o tempo presente, caracterizado pela proliferação de lugares para o depósito de lembranças em órgãos públicos e privados, clubes, escolas, hospitais, prisões, etc. Foi certamente essa "sedução pela memória" que mobilizou tal espaço a guardar e exibir seu passado, permitindo a preservação deste importantes acervo.

A experiência aqui analisada é fruto de um tempo recente, uma história inacabada, ainda prenhe de acontecimentos, que em seu desenrolar interpela o historiador. Como contemporânea desse processo, partilho com os sujeitos dessa tessitura as "mesmas categorias essenciais, as mesmas referências fundamentais", também divido com eles certa inquietação a respeito dos rumos do sistema penal na atualidade. Portanto, o texto que segue procura principalmente descrever, mas também e analisar a experiência vivida durante a realização de um estágio curricular que teve como seu produto final, uma exposição inaugurada dentro da Penitenciária de Florianópolis. A intensão do presente artigo é provocar a reflexão sobre a complexidade das relações estabelecidas dentro destes espaços, mostrando como ocorreu o processo de reconfigução do passado exposto, pensando neste como estratégia humanizadora, despertando a consciência critica sobre os rumos do sistema penal. 


\section{A EXPOSIÇÃO}

A relação dos detentos com tempo e a espera pela liberdade tornou-se o tema da exposição: "O tempo abre as portas a quem sabe esperar". A frase, que adorna uma das últimas grades com complexo, foi inspirada em um provérbio chinês de autoria desconhecida. Palavras são perspectivas, instituem significados. Esperar é ter esperança, é aguardar uma nova situação, é procurar a transformação. A exposição foi montada no local destinado ao Espaço Memória da Penitenciária, um amplo saguão no segundo andar do prédio administrativo da instituição.

A constituição de um lugar de memória ${ }^{8}$ dentro do Complexo foi uma demanda do Departamento de Administração Prisional (DEAP) e reflete uma preocupação social, pois, conforme citado anteriormente, existem reinvindicações que intencionam o tombamento parcial do Complexo devido a seu valor histórico. Neste processo, alguns detentos foram consultados sobre a possibilidade tornar a Penitenciária um museu": "Um museu não se resume somente a gravuras, papéis, fotos ou móveis antigos, mas sim a sensação de sentir, respirar e de certa forma viver ainda que seja por um instante o lugar em que se está" (Carta 1). Através de algumas cartas disponíveis no acervo é possível perceber que para os sentenciados um espaço museológico serviria apenas aos visitantes externos, para que estes, através dos vestígios deixados por "presos de outrora", percebam que dentro daquele espaço estigmatizado "estiveram pessoas iguais a eles. Simplesmente seres humanos" (Carta 2).

Desta forma, uma das preocupações centrais da nova exposição foi a questão do público alvo. Em conversa com a direção ficou estabelecido que teriam acesso ao espaço expositivo os detentos do regime semi-aberto que trabalhavam no prédio administrativo, os funcionários, os familiares dos detentos em dias de visita e turmas de universitários previamente agendadas. De que forma a proposta conceitual da exposição dialogaria com um público tão heterogêneo? Foi preciso dar inicio à vivência semanal de estágio dentro da instituição e ao trabalho de pesquisa para escolher os caminhos a serem trilhados.

Partiu-se então para a busca por suporte científico, com a realização um levantamento do acervo, identificação de fotografias e pesquisa documental e bibliográfica. Para iniciar o levantamento, a primeira tarefa colocada aos alunos foi a retirada das fotografias expostas, um trabalho que exigiu muito cuidado para que estas não fossem danificadas, higienizando e acondicionando o acervo composto por 150 imagens que abrangem um período compreendido entre 1930 até aproximadamente 1990. A grande maioria das imagens não tinha nenhuma identificação, sendo necessário recorrer a história oral, realizando entrevistas com alguns funcionários antigos, os quais foram essenciais nesse processo. Paralelo à isso foi efetuada uma pesquisa no Arquivo Público do Estado, a 
qual possibilitou a localização de um livro publicado pela Imprensa Oficial do Estado $^{10}$, o qual traz parte das imagens existentes no acervo, facilitando a identificação e a criação de legendas. Assim, através da história oral e da pesquisa arquivística, foi possível identificar o acervo fotográfico da instituição, permitindo a concepção das legendas utilizadas na exposição.

Dentre os objetos, expostos sem identificação no espaço Memória da Penitenciária, encontravam-se mesa, cadeira e sofá que pertenciam ao Gabinete do Diretor à época da inauguração, bem como uma Cadeira tipo viola. Esta era parte do Gabinete de Identificação, o qual possuía um quarto próprio para a revelação, um trabalho realizado conjuntamente com o Instituto de Identificação do Estado no anos 30, servindo de apoio para os presos sentarem-se para o registro da fotografia que acompanhava seu prontuário institucional. Havia ainda uma série de troféus de torneios de futebol realizados entre os detentos, que datavam das décadas de 1960 e 1970. Mantivemos esses objetos expostos, devidamente identificados e articulados com a proposta da nova exposição.

Perscrutando a instituição em busca de outros objetos e documentos, foi localizada uma documentação ainda não explorada, cerca de 5 mil prontuários de detentos, que datam da década de 1930, até fins da dácada de 1970. O acervo encontrava-se ameaçado por condições adversas a sua preservação, guardados em um depósito dentro do Complexo, para a exposição foi selecionada apenas uma pequena amostragem. ${ }^{11}$

Articular a aproximação do tema com o peculiar público alvo da exposição foi algo bem trabalhoso. Era preciso ainda considerar o peso disso na escolha dos objetos museológicos, fotografias e na construção dos discursos expositivo. A seleção obedeceu ao tema proposto, permitindo contar a história da instituição tendo como linha narrativa o tempo e a espera pela liberdade, perpassados assim pela ideia de transformação e de esperança. Para isso foram propostos dois Blocos que seguem uma ordem cronológica bem delimitada: Bloco 1 - Entre 1930 e 1940 e Bloco 2 - Entre 1950 e 1970.

O primeiro Bloco foi composto principalmente pelas fotografias do livro editado pela Imprensa Oficial do Estado em 1930, Penitenciária do Estado de Santa Catarina. As imagens procuram retratar a estrutura física e a organização interna da Penitenciária, destacando a construção de variadas oficinas, como a de móveis de vime, de encadernação, de costura, além de marcenaria, padaria, sapataria, etc. Tais atividades atendiam a própria instituição, bem como outros espaços como a Força Policial, o Abrigo de Menores, etc. Também se inserem nesse primeiro Bloco alguns objetos, como os móveis da sala do diretor e a Cadeira Tipo viola, que datam da inauguração da Penitenciária e ajudam a pensar como funcionava a estrutura interna em suas primeiras décadas.

O segundo Bloco é composto pelas fotografias da Semana do Sentenciado, um evento anual caracterizado por apresentações musicais de um "Conjunto" formado por detentos, e por torneios de futebol. Os objetos 
selecionados foram os troféus, os quais aparecem em várias fotografias do Esperança Futebol Clube, time formado por detentos.

Os prontuários selecionados perpassam os dois Blocos, envolvendo registros entre 1930 e 1970.

Figura 1 - Bloco I. Fotografias ampliadas do livro "Penitenciária do Estado de Santa Catarina"

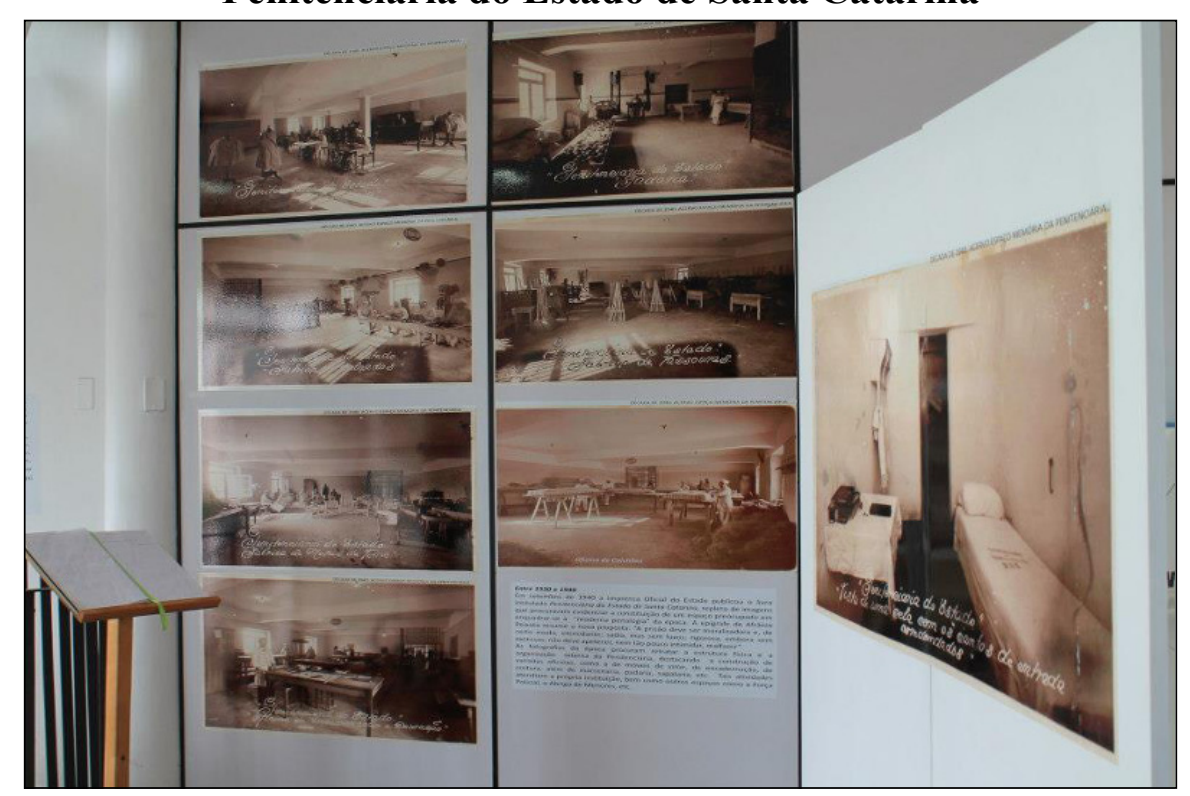

Fonte: Acervo da autora. 
Figura 2 - Bloco I. Cadeira tipo Viola e máquina fotográfica

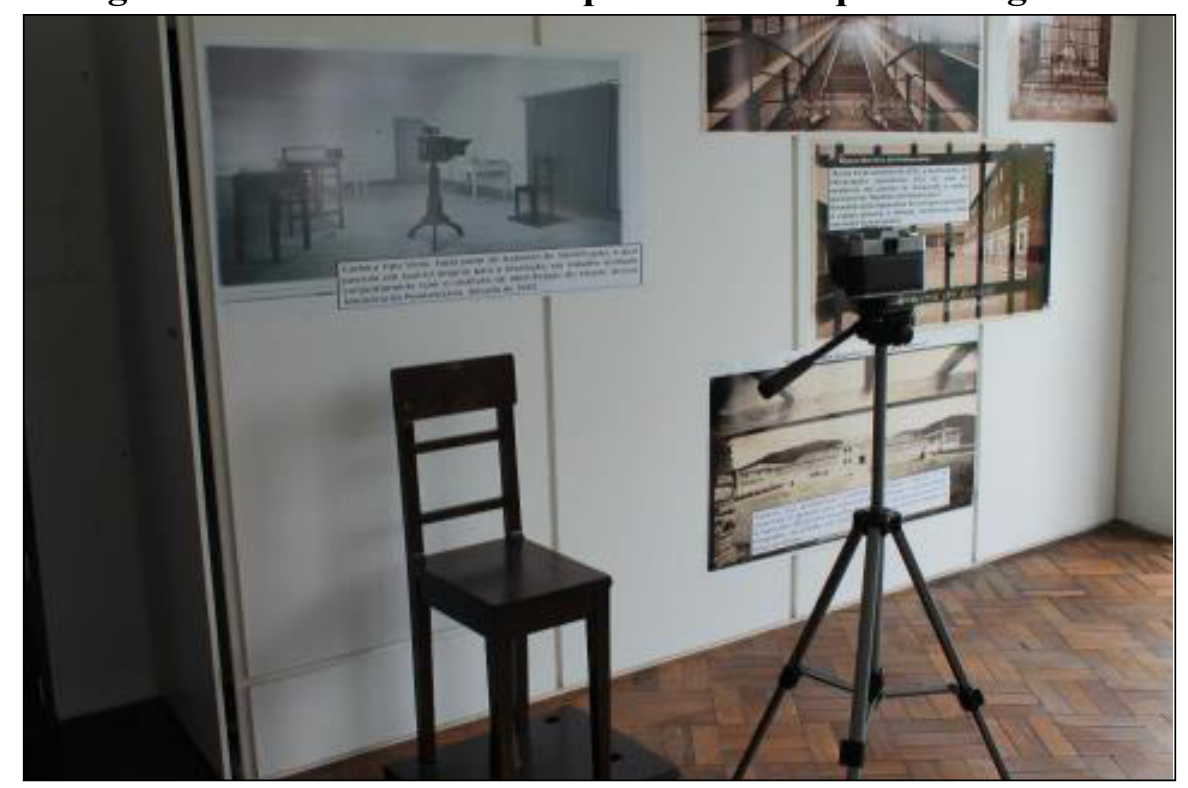

Fonte: Acervo da autora.

Figura 3 - Bloco I. Mobiliário da sala da direção

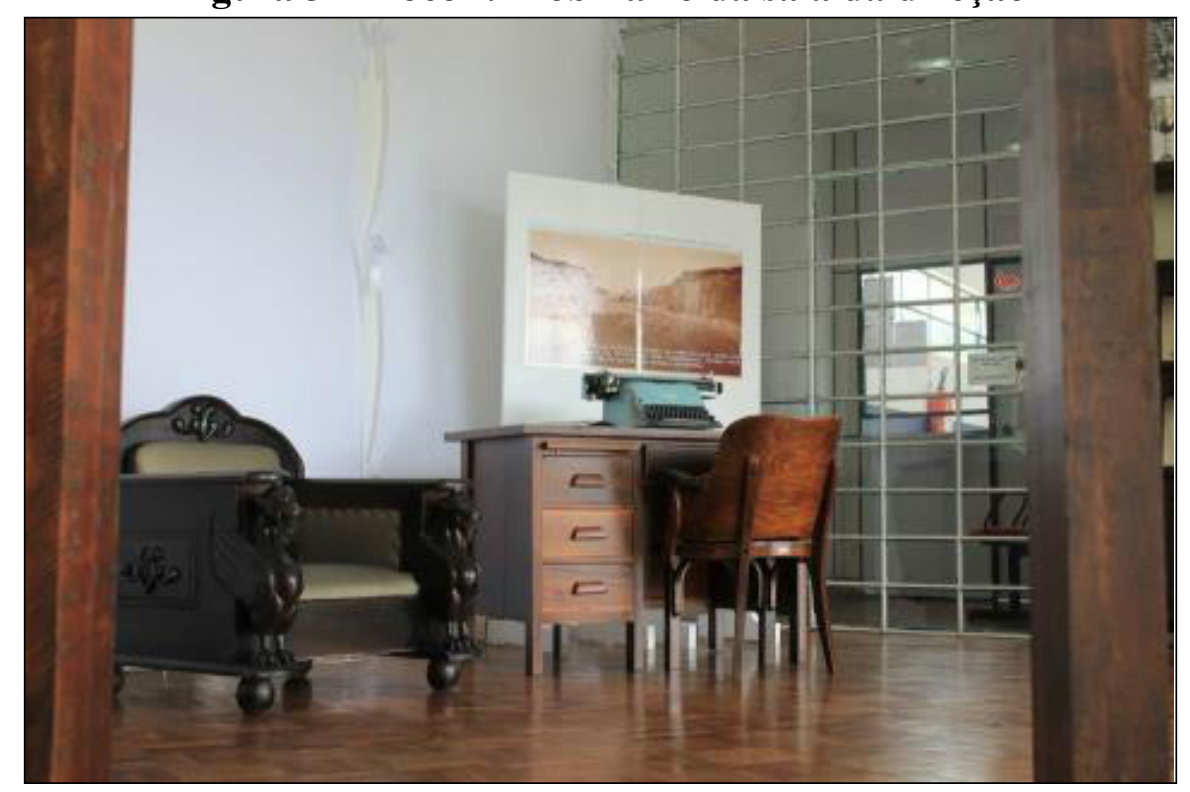

Fonte: Acervo da autora. 
Figura 4 - Bloco II. Troféus e fotografias dos torneios de futebol

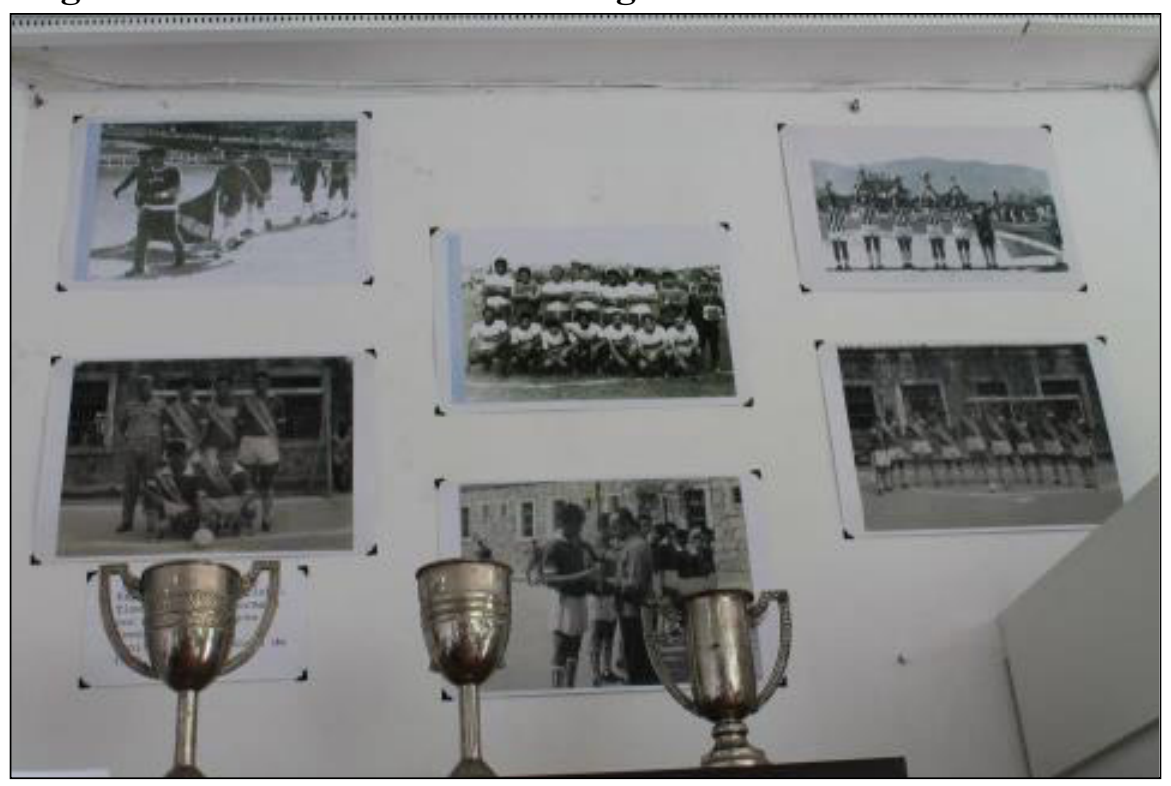

Fonte: Acervo da autora.

Figura 5 - Bloco II. Troféus

e prontuários expostos

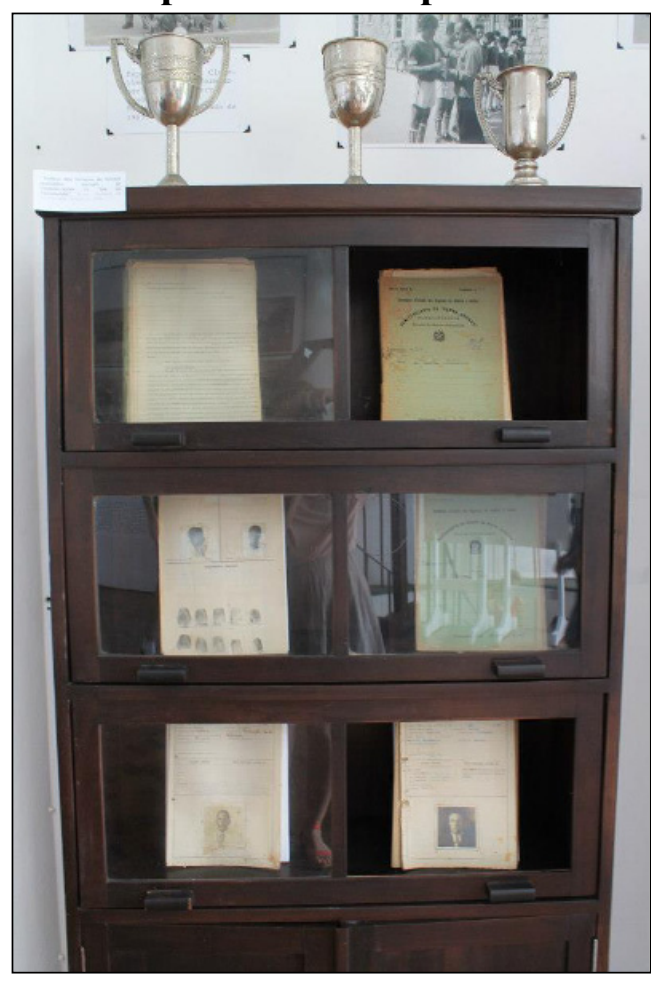

Fonte: Acervo da autora. 
A exposição seguiu portanto uma ordem cronológica que se encerra no final dos anos 70. Durante a pesquisa foi localizado um dossiê com reportagens que retratavam a história dos motins, da década de 80 até o inicio dos anos 2000 , além de fotografias referentes a este período mais próximo. A motivação que guiou a seleção do que faria parte da exposição atende ao tema proposto, mas também está diretamente ligada a vivência no campo de estágio. A realização do trabalho ocorreu durante os incidentes que marcaram o mês de novembro de 2012 em Santa Catarina, com uma série de ônibus queimados e ataques contra delegacias e postos da polícia militar. ${ }^{12} \mathrm{~A}$ onda de ataques teria sido coordenada por detentos da Penitenciária de São Pedro de Alcântara (SC), como forma de chamar a atenção da sociedade para as denuncias de tortura e maus tratos dentro da instituição. Tal situação estaria ligada ao assassinato da esposa do então diretor da instituição, em 26 de outubro, o qual passou a ser acusado de agressões contra detentos durante as investigações sobre o caso. ${ }^{13}$

Toda essa agitação reverberou diretamente na tessitura da exposição. O foco das tensões era São Pedro de Alcântara, contudo, a crise também reverberava na capital, Florianópolis, onde ocorreram grande parte dos ataques à ônibus do Estado. Apesar da Penitenciária de Florianópolis não estar no centro do conflito, existia um clima de preocupação, uma inquietação que perpassava corredores e grades. A dificuldade da equipe para entrar na instituição foi redobrada, pois a vigilância foi intensificada devido a crise. A equipe de estágio não se reunia mais em frente ao Complexo, pois em outras cidades houve casos de tiros disparados contra presídios e delegacias, existindo um receio de ataques à instituição. Também era perceptível a tenção dos funcionários frente a este momento de crise. Essa experiência serviu para a reflexão do grupo. Foi perceptível a complexidade que envolve as instituições carcerárias e as relações nelas estabelecidas. Durante o desenrolar do estágio, o Complexo tornou-se cada vez mais complexo, na medida em que acompanhávamos de perto um momento de tensão no sistema penal brasileiro, com a onda de ataques primeiramente em São Paulo e meses depois também em Santa Catarina. ${ }^{14}$

Assim, tratando-se de história do tempo presente, a presença do historiador no tema, imerso em seu tempo, oscila no fluxo da correnteza de acontecimentos. Cabe a este, como "bom artesão", superar a "falta de recuo" que muitas vezes desqualifica a história do tempo presente, "desempacotando sua caixa de instrumentos e experimentando suas hipóteses de trabalho", criando assim o necessário recuo em sua análise. ${ }^{15}$ Desta forma, contrapondo a documentação analisada com esse presente imediato que presenciávamos e vivíamos, foi possível perceber que a relação da comunidade e dos funcionários com o espaço da Penitenciaria alterou-se claramente com o passar do tempo. Atualmente existe uma demanda pela transferência do Complexo, frente as reinvindicações da população vizinha ao lugar, que teme a violência, e da sociedade em geral, que deseja levar para longe o espaço estigmatizado que 
macula um dos cartões postais da cidade, a Avenida Beira Mar. Além disso, há uma demanda por mais contratações de agentes penitenciários e um constante receio por parte de alguns destes, em relação à possíveis represálias de bandidos que executam ordens de detentos, os quais algumas vezes continuam a comandar o crime de dentro da prisão. Cabe citar ainda a superlotação, visto que o sistema prisional catarinense possui 17 mil condenados e capacidade para apenas 11 mil, situação esta que se repete pelo país, tomada como problema real e como objeto de debate:

\begin{abstract}
Atualmente, sabe-se que o crescimento descontrolado da violência alimenta o sistema prisional brasileiro com cada vez mais presos, desde 2006 este número ultrapassou 400 mil. [...] A superlotação carcerária afronta a condição humana dos detentos, aumenta a insegurança penitenciária, o abuso sexual, o consumo de drogas, diminui as chances de reinserção social do sentenciado, além de contrariar as condições mínimas de exigências dos organismos internacionais. O que fazer com os sentenciados e como corrigi-los sempre assombrou a sociedade. Punição, violência, correção. Conhecer a prisão é, portanto, compreender uma parte significativa dos sistemas normativos da sociedade. ${ }^{16}$
\end{abstract}

Neste cenário múltiplo, hostil e tenso, as memórias dos antigos funcionários e moradores da região ressaltam um período anterior, marcado por uma convivência mais pacífica. Nas décadas de 1930 e 1940 era comum festas dentro do espaço prisional, envolvendo a comunidade vizinha, a qual era constituída basicamente pelas famílias dos vigilantes, que acabaram adquirindo as casas da Vila Operária, construídas junto à Penitenciária, subvencionadas pelo Estado. Nas décadas de 1950 e 1960, agentes penitenciários e presos participavam de torneios de futebol que ocorriam dentro da Penitenciária. No acervo da instituição existem fotografias que documentam as premiações, como o Troféu entregue em 1968 ao Time Esperança Futebol Clube, formado por detentos. Na década de 1980, as rebeliões foram restringindo esse delicado convívio, culminando em um dos maiores motins seguidos de fuga da história do sistema carcerário do Estado, ocorrido em 1986, amplamente acompanhado pelos moradores locais, que se aglomeravam junto ao Complexo. ${ }^{17}$ Após esse evento, a chamada "Semana do Reeducando", festividade anual que envolvia comunidade, funcionários, autoridades locais e detentos, foi proibida e a repercussão através do jornais foi marcada por intensas reivindicações pela transferência do espaço para uma região menos urbanizada.

Durante as entrevistas que possibilitaram a identificação de objetos e fotografias, bem como nas conversas e no cotidiano da Penitenciária que 
pudemos acompanhar durante o estágio, observa-se claramente um embate entre as memórias de um presente perturbador, abalizado pela violência e insegurança, e um passado visto como mais ameno, perpassado pela esperança na recuperação dos detentos. O momento de crise vivido pelo sistema penal catarinense durante a tessitura da exposição, certamente reverberou nas rememorações dos entrevistados. Seguramente havia fissuras nesse passado idealizado, como mostra a documentação, através de, por exemplo, apontamentos nos prontuários que revelavam o uso de bebidas alcoólicas dentro da instituição, violência entre presos, reclamações de superlotação, precariedade das instalações, etc. Tais questões estão presentes na documentação selecionada, através de prontuários e escritos deixados por detentos ao longo dos anos. Contudo, esse passado idealizado torna-se uma necessidade do presente, uma forma de encarar os fatos mostrando que outras relações já foram possíveis naquele mesmo espaço.

Desta forma, a seleção do que seria abordado na exposição não foi algo arbitrário, mas resultado de um embate movido pelo momento vivido pelo sistema penal no Estado. A proposta era que o passado, mediado pelas técnicas pedagógicas e performativas da história, pudesse de alguma forma reverberar no social, contribuindo como estratégia humanizadora, provocando a reflexão e despertando a consciência critica sobre os rumos do sistema penitenciário. A perspectiva do passar do tempo, da esperança e da expectativa por transformação, é algo que se destaca na construção da imagem da penitenciária entre a década de 1930 e final dos anos 70, principalmente quando comparada aos dias atuais. Optou-se por abordar essa época quase idílica, evidenciada pelas fotografias e relatos que desvelam um período em que o Complexo, ainda que enfrentando problemas, parece bem menos complexo que na atualidade.

"Neste sentido, o historiador dá a sociedade sua memória, seus laços com o passado a fim de que possa viver melhor com seu presente". ${ }^{18} \mathrm{O}$ que fica exposto é a problemática histórica, ou seja, a possibilidade de outras relações dentro daquele espaço, incitando a reflexão a respeito dos caminhos trilhados sistema penal. Conforme Ramos, "a história deixa de ser passado morto para emergir como pretérito eivado de presente, pois a questão dos poderes em conflito também diz respeito ao mundo no qual vivemos". ${ }^{19}$ Assim, objetos e fotografias selecionados para que fazerem parte da exposição, possuem um compromisso com o presente, "é no presente que eles são produzidos ou reproduzidos como categoria de objeto e é às necessidades do presente que eles respondem. ${ }^{20}$ São "objetos portadores de sentido", evidenciam que um outro tipo de relação já foi possível, inspiram as discussões que apontam novos rumos ao velho Complexo. O presente portanto foi o foco ordenador. O decurso do tempo constitui fator relevante de qualificação dos objetos e fotografias selecionados para compor a exposição, eles remetem a um passado idealizado como mais tranquilo, parecem ajudar a acalmar um presente pleno em conflitos. 
Em relação ao diagnóstico dos recursos disponíveis, tivemos uma série de limitações que motivaram a busca por soluções possíveis e criativas. Cerca de 20 fotografias foram ampliadas (tamanho: $1,15 \times 0,60 \mathrm{~m}$ ) com recursos da UDESC e ainda 5 imagens foram impressas pelo Arquivo Público do Estado. A oficina de marcenaria da Penitenciária providenciou alguns expositores e a direção permitiu a plotagem de paredes do Espaço Memória. Para expor os documentos selecionados utilizamos um armário que estava em desuso, aproveitando que o mesmo possuía portas de vidro. Nosso cronograma, de cerca de 4 meses para desenvolver o projeto, foi cumprido com alguns dias de atraso que levaram a exposição a ser inaugurada em dezembro, após o término do semestre letivo. Desta forma, os alunos continuaram a executar suas atividades mesmo depois do encerramento da disciplina, uma prova da motivação que dominou o grupo..$^{21}$

O produto, resultado final da intervenção dos alunos por mim coordenada foi portanto uma exposição, resultado de um processo de concepção e montagem que procurou oferecer uma nova experiência para o público, utilizando um acervo já conhecido, mas agora identificado e reconfigurado, através da ampliação e identificação das imagens e objetos e sua disposição no espaço. Certamente deixamos de abordar questões atuais e importantes, como a história dos motins, por exemplo, mas não era essa a proposta da exposição. A ideia foi estabelecer uma relação dialética entre o conhecimento que funcionários, detentos, familiares e publico externo já tinham sobre o tema e o novo conhecimento que a exposição está propondo, conectada com suas experiências anteriores, procurando influenciar positivamente suas experiências futuras, humanizando o lugar ${ }^{22}$, mostrando que atrás dos muros altos e das grades, existem "simplesmente seres humanos" (Carta 2).

Os efeitos expográficos puderam ser sentidos na inauguração, o público caminhava pelo espaço, observava, julgava, comparava, apreciava, lembrava e se emocionava. Os funcionários antigos eram tomados por rememorações, queriam compartilhar informações sobre como era aquele espaço em períodos anteriores. Os detentos que auxiliaram na montagem ficaram impressionado com as mudanças sofridas pelo lugar, comparavam o "antes" e o "depois", tentando reconhecer os lugares retratados. Alguns funcionários mais recentes e também familiares dos sentenciados, que comumente circulam pelo prédio administrativo, pareciam surpresos com a nova roupagem que transformava o lugar já conhecido. $\mathrm{O}$ evento contou com uma apresentação musical, na qual duas canções foram executadas, ambas perpassadas pela abordagem do passar do tempo: Oração ao tempo (Caetano Veloso) e Time is on my side (Rolling Stones). Nesse dia, violão, voz e violino ressonaram por corredores e grades, trouxeram a leveza e potencializaram os efeitos da exposição, mostrando que outras relações ainda são possíveis nesse espaço. 


\section{NOTAS}

${ }^{1}$ O presente estudo é um desdobramento do projeto Patrimônio, memória e loucura: o acervo do Hospital Colonia Sant'Ana (SC/1940-1995), o qual recebeu auxílio do CNPq através do Edital Universal (2011). Pesquisar sobre a Penitenciária de Florianópolis foi uma demanda da referida pesquisa, que visa problematizar a constituição do Hospital Colônia Sant'Ana, salvaguardando seu acervo, além de mapear espaços de memória criados em lugares estigmatizados como hospitais psiquiátricos, leprosários e prisões. No desenrolar da pesquisa foi constatado que parte dos internos transferidos para o Hospital vinham da Penitenciária, tornando-se fundamental analisar os prontuários destes também dentro do Complexo, problematizando a tênue linha que muitas vezes separa crime e loucura.

${ }^{2}$ Desde a década de 1980 vem sendo pensadas alternativas para a construção de um novo Complexo, Palhoça e Paulo Lopes foram localidades apresentadas como opções, mais recentemente foi decidido como sede o Município de Imaruí, no sul do Estado.

${ }^{3}$ A Notícia, 10 jan. 2007.

${ }^{4}$ A exposição foi possível graças ao envolvimento e apoio dos alunos da disciplina de Patrimônio Cultural do curso de História da UDESC: Carlos Eduardo Oliveira, Fernanda Cassetari, Henderson Lima, João Paulo Caetano, Líbia de Haro, Silvia Viatorassi, Willian Conceição da Luz e de uma aluna do curso de Museologia da UFSC, Ligia Missio, e do colega de departamento da UDESC Prof. Dr. Rogério Rosa Rodrigues.

${ }^{5}$ SCHMIDT, Benito; SPERANZA, Clarice. Processos trabalhista: de papel velho a patrimônio cultural. In: PAULA, Z.C. de. MENDONÇA; L. ROMANELLO, J.L. Polifonia do patrimônio. Londrina: Eduel, 2012. p. 254.

${ }^{6}$ HUYSSEN, Andreas. Seduzidos pela memória. Rio de Janeiro: Aeroplano/Universidade Cândido Mendes/Museu de Arte Moderna do Rio de Janeiro, 2000.

${ }^{7}$ CHARTIER, Roger. A visão do historiador modernista. In: FERREIRA, Marieta de M.; AMADO, Janaína. Usos \& abusos da história oral. 3. ed. Rio de Janeiro: FGV Editora, 2000. p. 216.

${ }^{8}$ Sob a perspectiva de Pierre Nora (NORA, Pierre. Entre memória e história: a problemática dos lugares. Projeto História, São Paulo, n. 10, p. 7-28, dez. 1993. Disponível em: <http:// www.pucsp.br/projetohistoria/downloads/revista/PHistoria10.pdf $>$. Acesso em 7 fev. 2012.), para que existam lugares de memória é necessário uma vontade de memória, organizando o que deve ser lembrado de forma intencional e seletiva. Os caminhos trilhados pela recepção deste conceito resultaram em apropriações diversas e por vezes conflitantes. A noção ganhou novos usos, os quais por vezes se afastam da problematização crítica a respeito dos usos do passado e das batalhas de memórias, incitadas por Nora, caminhando para uma banalização elogiosa sobre o passado recordado. Tal noção é aqui utilizada para problematizar os usos do passado através da constituição de um espaço destinado à rememoração dentro de uma instituição penal em Santa Catarina. A respeito da contribuição do historiador Pierre Nora para os estudos relacionados ao campo do patrimônio cultural e os percursos da perspectiva dos lugares de memória, ver GONÇALVES, Janice. Pierre Nora e o tempo Presente: entre a memória e o Patrimônio cultural. Historiae, Rio Grande, v. 3, n. 3, p. 27-46, 2012.

${ }^{9}$ São cartas escritas por detentos do regime semi-aberto, que hoje fazem parte do acervo do Espaço Memória da Penitenciária. As mesmas foram escritas em virtude de um trabalho realizado pela funcionária da instituição e graduanda em Museologia, Ligia Missio. São cindo cartas, escritas em 2011, nas quais alguns detentos escreveram o que pensavam a respeito da idéia de a penitenciária tornar-se um Museu. 
${ }^{10}$ Em setembro de 1940 a Imprensa Oficial do Estado publicou o livro intitulado Penitenciária do Estado de Santa Catarina, repleto de imagens que procuravam evidenciar a constituição de um espaço preocupado em enquadrar-se à "moderna penalogia" da época.

${ }^{11}$ Através do Projeto de extensão "Arquivos marginais", por mim coordenado, foi dado início a salvaguarda do acervo ameaçado, o qual foi cedido temporariamente ao IDCH. Instituto Investigação em Ciências Humanas, pertencente à UDESC. O projeto conta atualmente com o apoio de dois bolsistas de extensão, dois bolsistas de Iniciação Científica e 9 voluntários.

${ }^{12} \mathrm{O}$ saldo dos ataques em Santa Catarina foi de 25 ônibus incendiados, cinco tentativas de incêndios a ônibus, 18 veículos incendiados ou tentativas de incêndio e uma viatura queimada, além de ataques contra delegacias e postos da polícia. Disponível em: $<$ http://www. centraldediarios.com.br/editoriais/politica/ssp-se-reune-para-discutir-novas-acoes-contraataques/1531.html> . Acesso em: 24 jan. 2013.

${ }^{13}$ Disponível em: $<$ http://noticias.uol.com.br/cotidiano/ultimas-noticias/2012/11/14/governoafasta-diretor-de-presidio-para-por-fim-a-onda-de-violencia-em-santa-catarina.htm $>$. Acesso em : 22 de jan. de 2013.

${ }^{14}$ A onda de ataques à ônibus e policiais militares em São Paulo teve início em junho de 2012.

${ }^{15}$ RIOUX, Jean-Pierre. Pode-se fazer uma história do presente? In: BECKER, J. J. et. al. Questões para a história do presente. Bauru: EDUSC, 1999. p. 41 e 46.

${ }^{16}$ MAIA, Clarissa Nunes et al. História das prisões do Brasil. Rio de Janeiro: ROCCO, 2009. p. 10 . v. 1

${ }^{17} \mathrm{O}$ motim foi provocado por detentos que se aproveitaram da solenidade anual da "Semana do Reeducando", para render as autoridades da segurança pública e justiça do estado. Dezessete presos fizeram cinco reféns e fugiram em três automóveis. Os reféns foram liberados ao longo dos dias, mas nem todos os detentos foram recapturados. A partir desse episódio as comemorações da Semana do Reeducando foram suspensas.

${ }^{18}$ FARGE, A. Lugares para a História. Belo Horizonte: Autentica, 2011. p. 13.

${ }^{19}$ RAMOS, F.R.L. A danação do objeto: o museu no ensino de História. Chapecó: Argos, 2004. p. 23.

${ }^{20}$ MENESES, U.T. B. de. A exposição museológica e o conhecimento histórico. In: FIGUEIREDO, Betânia Gonçalves; VIDAL, Diana. Museus do Gabinete de curiosidades à museologia moderna. Belo Horizonte: Argvmentvm/Brasília: CNPQ, 2005. p. 26.

${ }^{21}$ Os ensaios produzidos pelos alunos foram reelaborados e publicados na Revista de História Catarina (2012). Também foi publicada uma matéria na Revista de História da Biblioteca Nacional (2012), intitulada "Fotografias atrás das grades". ROMANELLI, Cristina. Fotografia atrás das grades. Revista de História da Biblioteca Nacional, Rio de Janeiro, ano 8, n. 87, dez. 2012.

${ }^{22}$ CURY, M. X. Exposição: concepção, montagem e avaliação. São Paulo: Annablume, 2006. p. $43-44$.

\section{Artigo recebido em setembro de 2013. Aceito em julho de 2014.}

